\title{
An Evidence-Based Possible Framework for Addressing Economic and Health Challenges of the Ageing Population in Bangladesh
}

\author{
Mohammad Mastak Al Amin \\ BRAC University, Bangladesh
}

\begin{abstract}
Political unrest, poor economic growth, low savings and tiny coverage of pension are making the elderly to face challenges to survive in Bangladesh. Health care costs of elderly affected their household living standard significantly due to the unbalanced financial liability in Bangladesh. In this study, we conducted a survey on elderly of 311 sample size from four thana: Dhanmondi, Gulshan, Uttara and Mohammadpur in Dhaka City. Both probability and non-probability sampling methods were used to collect demographic, economic, and health related information of elderly. Elderly mostly depend on their family and pension for their financial support at their retirement age, while they rarely depend on insurance in Bangladesh. Besides, price inflation is another cost driver for elderly. This paper focuses on exploring the current state of health and economic position of elderly. Therefore, the logistic regression model was derived to identify the significant key factors (income, pension, health Insurance, physical independence $\&$ gender) which were influencing the treatment cost of elderly. Hence, our study also suggests the policy implications (such as specialized bank, social insurance authority, security alert apps, subsidies catering companies, specialized pharmacies etc.) for the upcoming ageing challenges in Bangladesh.
\end{abstract}

Keywords: Population ageing, social insurance, health care services, Bangladesh

\section{Introduction}

People are living longer because of increased life expectancy. This is one of the main reasons for elderly growth not only in Bangladesh, but also in the whole world (Bengtsson \& Scott, 2011). On an average, life expectancy for female has increased almost at a constant rate of 3 months per year from 1840, which is slightly slower for the male (Oeppen \& Vaupel, 2002). As a 
consequence of this fact, generations after generation of children are living about 9 years more than their parents. This scenario is also been upheld by the other developed countries such as Sweden, Norway, Australia, and New Zealand. About $7 \%$ of the total population of Bangladesh are elderly (Rahman, 2010). There are various factors for growing ageing population, particularly greater life expectancy, and a declining fertility and mortality rates. Demographic transitions, economic repercussion, and recessions are being overlapped over time as a result of population ageing which is threatening for the developed countries as well as for the developing countries. In every country, males and females played diverse role, obtained different rewards, and experienced different realities causing different life expectancy (Sultana, 2011). The mean age of the population is increasing due to long life. On the other hand, declining fertility tends to reduce the number of children, lower the mortality rate, and extend the endurance of the elderly (Ali, 2013). It was found that due to a considerable improvement of health and medical services, mortality began to fall after World War II (Michel \& Robine, 2004). Population ageing is taking place at different period of time for each country. Particularly for Sweden, population ageing has taken many years; but in the case of Bangladesh, the same transition had taken less time (Rowshon, 2012). It has been projected that the world will have roughly 800 million elderly people by 2025 where the major role will be played by the Asian countries. The United Nations estimated that $36 \%$ of Japanese, $35.9 \%$ of Italian, $31 \%$ of German, 30.4\% of Swedish, $22.7 \%$ of China, $14.8 \%$ of Indian, and $11 \%$ of Bangladeshi will be 65 years or above by the year 2050 (Rahman, 2012).

In Bangladesh, people are growing older before the age of 60 years due to poverty, physical hard work, malnutrition, and geographical conditions. In contrast, the growth of elderly is rising because of reduction in fertility, decline in infant and maternal mortality, and fall in infectious and parasitic diseases, the modern healthcare facilities, education, and income. Out of 160 million people in Bangladesh, about 10 million elderly are facing a daunting challenge in order to have social security and proper health care services. Morever, the life expectancy is increasing rapidly in Bangladesh. It was 70.1 years in 2011 and was estimated to reach 80.5 years in 2070. If this growth is upholding in Bangladesh, the population pyramid will become rectangular in the coming decades. Hence, it is indispensable to anticipate the future estimate of elderly population in Bangladesh to unravel the upcoming challenges. However, large portion of a person's savings was spent for treatment due to lack of health insurance coverage in Bangladesh (Jeremy et al., 2015). As we all know, the insurance coverage led to a decrease in the financial barriers of getting proper treatment. On the other hand, the dependent health care coverage expansion is connected with an upsurge in 
insurance coverage (McClellan, 2017). It was noticeable that the health insurance coverage has increased in private health insurance among the middle-income and high-income young adults (Look \& Arora, 2016). In a bid to get several medical services with minimal cost, Bangladeshis saw the need to travel outside Bangladesh (Schultz et al., 2014). Moreover, the total fertility rate of Bangladesh reduced from 6.3 in 1971 to 2.3 in 2011 (BDHS, 2011), which is expected to reduce towards replacement level (2.2) by 20452050 (UN, 2005). Furthermore, in Bangladesh, life expectancy has increased from 36.6 years in 1950-1955 to 69.75 years in 2011, and is expected to rise to 79.20 years by the year 2045-2050 (WPP, 2012).

In Bangladesh, $7.48 \%$ (about 10 million) of the total population is elderly according to the latest 2011 census that can be seen in the population pyramid. About 8 million of elderly live in rural areas with poverty, malnutrition, and perilous geographical condition. After the liberation of Bangladesh in 1971, elderly population has rapidly increased over the last few decades.
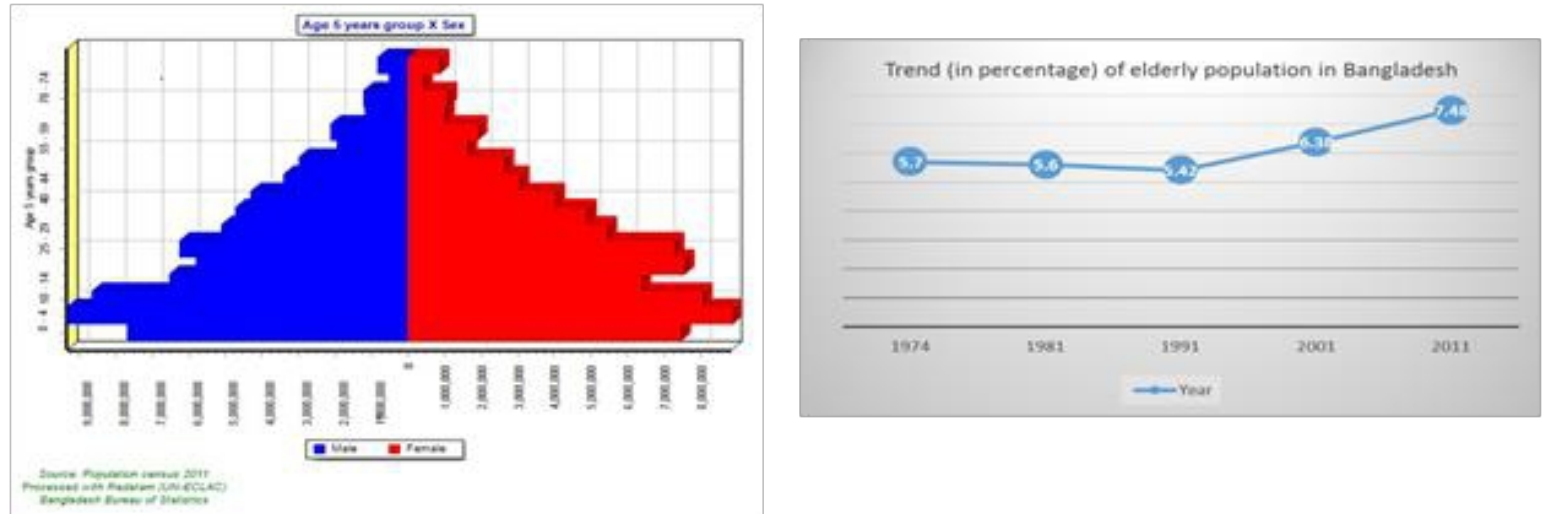

Figure 1. Population pyramid (5 years group) and trend of elderly population in Bangladesh

The elderly populations in Bangladesh were $5.7 \%, 5.6 \%, 5.42 \%$, and $6.38 \%$ respectively according to the census held in 1974, 1981, 1991, and 2001.

The elderly population are experiencing a difficult time with their condition of socio-economic transformation in Bangladesh. For successful ageing, there are many social theories of ageing dealing with social relations and social activities that recommended that elderly people should be socially active in their later age (Bergstrom, et al., 2000).

The objective of our study is to explore the current scenery of ageing population in Bangladesh and discuss few prospective policy implications of elderly people. The study is mainly divided into two parts. In the first part, we try to discuss about the state of elderly and the significant factors associated with the situation from different perspectives (demographic and economic). 
On the other hand, the second part suggests the future policy implications for elderly in Bangladesh.

\section{Data and Methodology}

Although few researches on ageing population in Bangladesh are available, economic and health implications policies have been barely examined. Thus, more research should be conducted to analyze the economic factors related to health policies of Bangladeshis elderly in a comprehensive manner. Population ageing is generally considered in employing a cross sectional technique (Islam, 2008). Therefore, a cross sectional data analysis type study design was applied for our study which comprised of the retrospective information of elderly. A preliminary semi-structured questionnaire was first developed and pre-tested several times to arrive at appropriate wording, format, length and sequencing of questions. In this regard, emphasis was placed on demographic information, socio-economic conditions, health care, life satisfaction, psychological problem, etc. (Vedder \& Virta, 2005). A small team of third year students of BRAC University were employed for data collection. They were briefed about the objective and the questionnaire of the study. The questionnaire included questions on demographic, socio-economic, health related, and the psychological aspects of the respondents.

\section{Data Collection and Sampling Methods}

The population of our research comprised of Bangladeshi elderly who had already experienced their $60^{\text {th }}$ birthday. Due to the poor level of education in Bangladesh, there are difficulties to obtain the exact age of elderly. Another limitation of this study is that in Bangladesh, we did not have a very good population registration system. In our study, Dhaka, the capital of Bangladesh, was chosen as a study sample to take advantage of its dense urban population. To collect the data of the aging population, we used two stage sampling methods of both probability and non-probability sampling techniques: simple random sampling and convenience sampling. It is worthy to note that nonprobability sampling techniques have some limitations due to the subjective nature, even though they are more useful in case of large population when we do not have the chance to use the probability sampling in all circumstances. To represent the population, four thana named Dhanmondi, Gulshan, Uttara, and Mohammadpur were selected by using simple random sampling from the forty six Thana situated at Dhaka city. Face to face interview method was used to collect information from 311 completed surveys by using the convenience sampling for gathering information of elderly. Here, 300 of them were retained, while 11 of them had excessive missing data. Besides these, a major source of information was taken from the latest 
population census data (2011) and from various international renowned organizations who were working on ageing population.

\section{Statistical Techniques}

In our study, we used various statistical techniques such as uni-variate and bi-variate table to analyze and identify the significant factors. For univariate level, we mainly focused on preparing frequency distribution and graphical presentation. We also used the statistical technique 'multinomial logistic regression analysis' to study the effect of different factors such as 'health insurance coverage, pension, gender, physical independence and income' related to the dependent variable 'treatment cost'. We preferred 'multinomial logistic regression analyses' because the dependent variable has more than two categories. Regression analysis is used mainly for investigating and modeling the relationships between variables (Montgomery, 1992, p.1). In our dataset, we considered five categories (very high, high, moderate, low and very low) for the dependent variable 'treatment cost'. Also, we analyzed the data by using Statistical software SPSS (Statistical Package for Social Science).

\section{Analysis and Discussion \\ Demographics of Elderly}

Demographic features such as marital status, years of schooling, and occupation had been measured to apprehend the selectivity process of elderly.
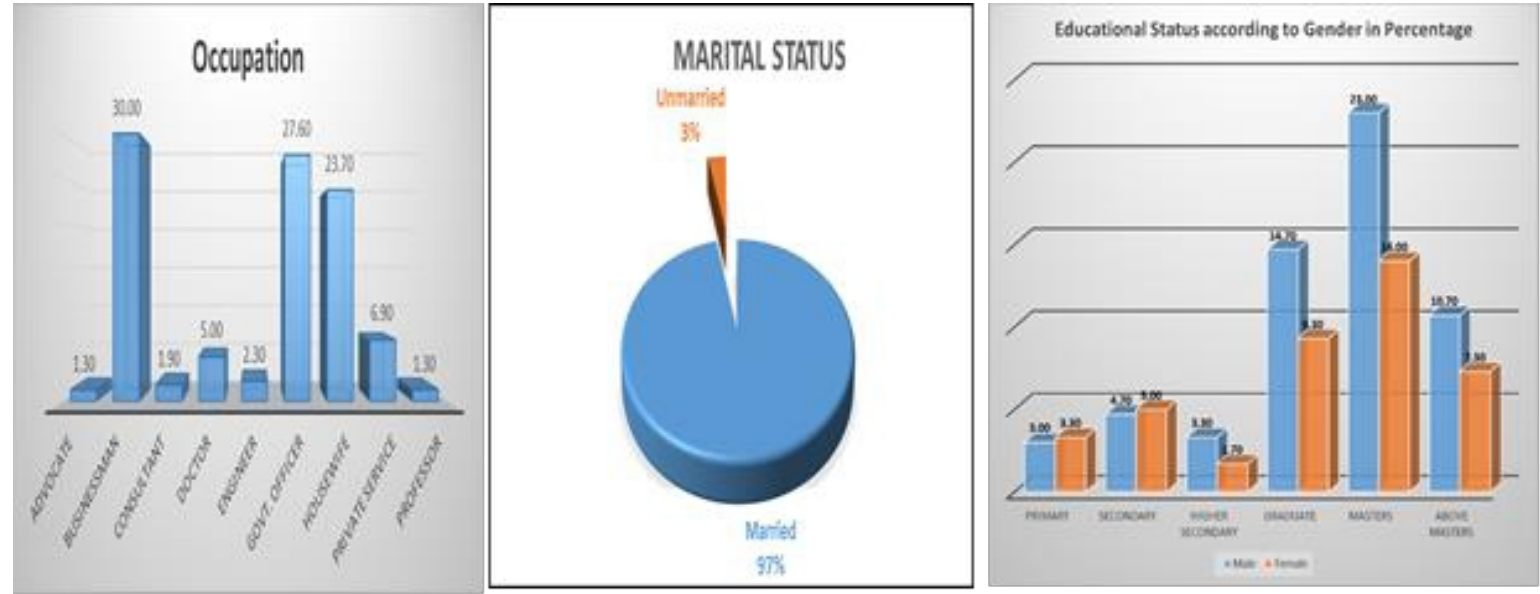

Figure 2. Occupation, marital status and education status of respondents

In our dataset, the percentages of married and unmarried elderly were 97\% and 3\% respectively. Our study illustrated that the highest percentage (30\%) of the respondents were businessmen, $27.6 \%$ of the respondents were Government officers, $23.7 \%$ of the respondents were housewives, and $6.9 \%$ 
respondents were from private services. Moreover, in the dataset, $1.3 \%$ were Advocates, $1.9 \%$ were Consultants, $5 \%$ were Doctors, and $2.3 \%$ were Engineers. In addition, the highest percentage of the respondents completed their post-graduation or further level of education for both male $(33.7 \%)$ and female $(21.3 \%)$.

\section{Economic State of Elderly}

In 1958, renowned American economist, Paul Samuelson, argued how consumption might be maintained throughout the life cycle. According to his overlapping-generations model, an individual's life cycle was divided into two periods: as a productive worker and an unproductive retiree. He considered the example of fruits worker that cannot be saved whether consumed instantly. Consequently, he tried to imply that all retirees were dependent and was unable to save for their own retirement. The probable solutions suggested by Samuelson were (1) a family system with transfers from working children to their retired parents, (2) the creation of 'fiat money (fiat money is the money supported by an authority, usually a government) as a store of value that can be saved by the workers, (3) formation of an integrated social security system. Transfers from worker to retired person through any of this mode will lead to progress in welfare for all persons. In order to consider the current social security system in Bangladesh, it was found that elderly mostly rely on the next generation to attain all kind of supports during their retirement period (Jalal \& Younis, 2014). Our dataset depicted that highest percentage $(41.3 \%)$ of elderly spent 10000-30000 BDT monthly for their treatment cost. There was an indication that closeness to death rather than ageing was the key factor for health expenditure. Moreover, income was extremely statistically significant to health expenditure in Bangladesh. Major portion of the income at old age were required to be spent on treatment cost due to lack of health insurance coverage in Bangladesh.
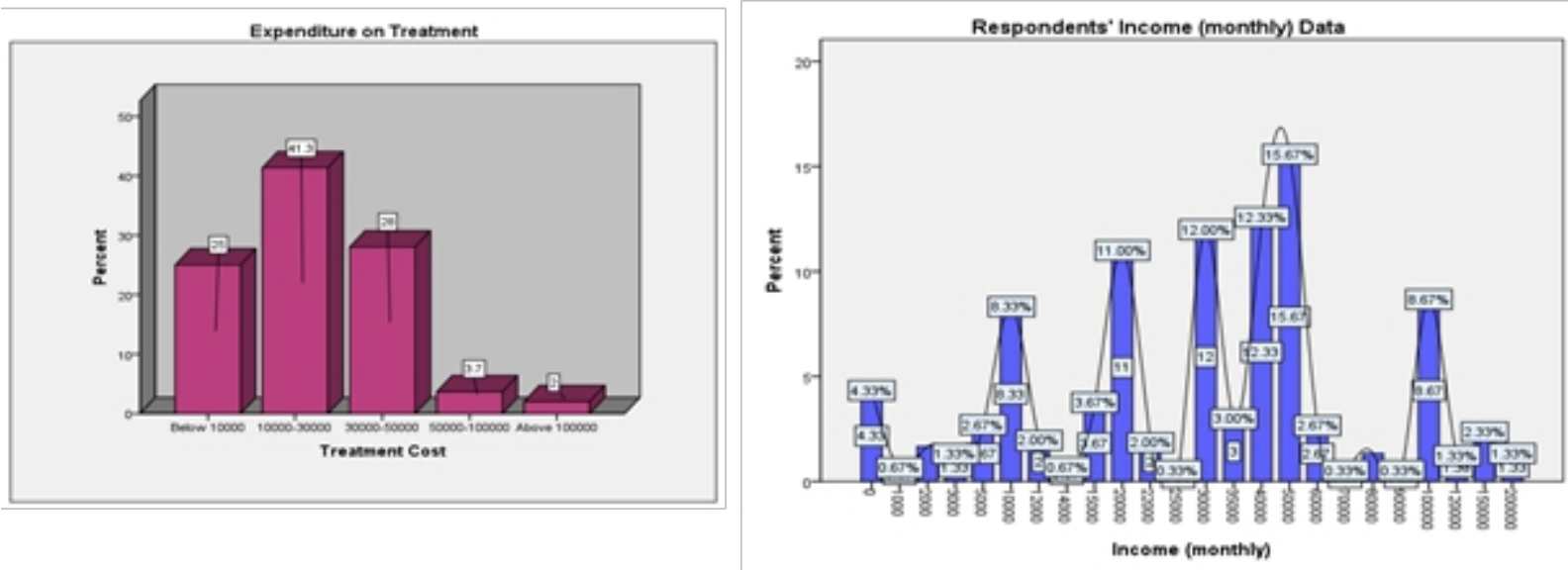

Figure 3. Respondents' treatment cost and monthly income 
Cross Tabulation of Economic Independence and Gender

\begin{tabular}{|cc|c|r|c|}
\hline \multirow{2}{*}{} & & \multicolumn{2}{|c|}{ Economic Independence } & \multirow{2}{*}{} \\
\cline { 2 - 4 } & \multicolumn{1}{|c|}{ Yes } & \multicolumn{1}{|c|}{ No } & Total \\
\hline \multirow{2}{*}{ Gender } & Male & $54.6 \%$ & $4.7 \%$ & $59.3 \%$ \\
\cline { 2 - 4 } & Female & $34.7 \%$ & $6.0 \%$ & $40.7 \%$ \\
\hline \multicolumn{2}{|c|}{ Total } & $89.3 \%$ & $10.7 \%$ & $100.0 \%$ \\
\hline
\end{tabular}

Table 1. Cross tabulation of gender and economic independence

Considering the economic independence according to gender, $89.3 \%$ of the elderly were economically independent while only $34.7 \%$ women were economically independent in our dataset (Table1).

\section{Statistical Analysis (Multinomial Logistic Regression) of the Impact of Key Economic Factor 'Treatment Cost'}

The scientific aim of our study is to consider the economic factors of health management difficulties with the existing living standard of elderly. Here, we tried to develop the multinomial logistic regression model to identify and measure the impact of economic factor 'Treatment cost' with associated explanatory variables such as income, pension, health insurance, physical independence, and gender. Percentages of respondents of different categories for the dependent and independent variables were summarized in Table 2.

\begin{tabular}{|c|c|c|}
\hline \multicolumn{3}{|c|}{ Variables Summary } \\
\hline & & $\begin{array}{l}\text { Percentage of } \\
\text { Respondents }\end{array}$ \\
\hline \multirow[t]{5}{*}{ Treatment cost } & Very low & $25.0 \%$ \\
\hline & Low & $41.3 \%$ \\
\hline & Moderate & $28.0 \%$ \\
\hline & High & $3.7 \%$ \\
\hline & Very high & $2.0 \%$ \\
\hline \multirow[t]{2}{*}{ Pension status } & Yes & $44.3 \%$ \\
\hline & No & $55.7 \%$ \\
\hline \multirow[t]{2}{*}{ Health Insurance coverage status } & Yes & $15.7 \%$ \\
\hline & No & $84.3 \%$ \\
\hline \multirow[t]{2}{*}{ Physically independence } & Yes & $96.3 \%$ \\
\hline & No & $3.7 \%$ \\
\hline \multirow[t]{2}{*}{ Gender } & Male & $59.3 \%$ \\
\hline & Female & $40.7 \%$ \\
\hline
\end{tabular}

Table 2. Summary of independent and dependent variables

Furthermore, we had an overall image of the model from the 'Model Fitting Information' in Table 3. It showed that the explanatory variables were very much statistically significant $(\mathrm{p}=0.00)$ to depict the 'Treatment cost' precisely. 
Model Fitting Information

\begin{tabular}{|c|c|c|c|c|}
\hline Model & $\begin{array}{c}\text { Model Fitting } \\
\text { Criteria }\end{array}$ & \multicolumn{3}{|c|}{ Likelihood Ratio Tests } \\
\cline { 2 - 5 } & $\begin{array}{c}-2 \text { Log } \\
\text { Likelihood }\end{array}$ & Chi-Square & df & Sig. \\
\hline Intercept Only & 521.296 & & & $\mathbf{. 0 0 0}$ \\
\hline Final & 365.015 & 156.281 & 20 & \\
\hline
\end{tabular}

Table 3. Summary of multinomial logistic regression model fitting information

\begin{tabular}{|c|c|}
\hline \multicolumn{2}{|c|}{ Pseudo R-Square } \\
\hline Cox and Snell & .406 \\
\hline Nagelkerke & .441 \\
\hline McFadden & .205 \\
\hline
\end{tabular}

Table 4. R-square summary table of multinomial logistic regression model

Pseudo R-Square in Table 4 depicted that the dependent variable 'Treatment cost' in the model explained $40.6 \%$ according to Cox and Snell pseudo R-Square measure, $44.1 \%$ according to Nagelkerke pseudo R-Square measure, and $20.5 \%$ according to McFadden pseudo R-Square measure by all considered independent variables which are income, pension status, health insurance status, physical independence, and gender.

\begin{tabular}{|c|c|c|c|c|}
\hline \multicolumn{5}{|c|}{ Likelihood Ratio Tests } \\
\hline \multirow{2}{*}{ Effect } & Model Fitting Criteria & \multicolumn{3}{|c|}{ Likelihood Ratio Tests } \\
\cline { 2 - 5 } & $\begin{array}{c}\text {-2 Log Likelihood of } \\
\text { Reduced Model }\end{array}$ & Chi-Square & Df & Sig. \\
\hline Intercept & 365.015 & .000 & 0 &. \\
\hline Income & 456.169 & 91.153 & 4 & $\mathbf{. 0 0 0}$ \\
\hline Pension Status & 375.017 & 10.002 & 4 & $\mathbf{. 0 4 0}$ \\
\hline $\begin{array}{c}\text { Health Insurance } \\
\text { Status }\end{array}$ & 370.220 & 5.205 & 4 & .267 \\
\hline $\begin{array}{c}\text { Physical } \\
\text { Independence }\end{array}$ & 382.113 & 17.098 & 4 & $\mathbf{. 0 0 2}$ \\
\hline Gender & 373.992 & 8.977 & 4 & $\mathbf{. 0 6 2}$ \\
\hline
\end{tabular}

Table 5. Summary table of likelihood ratio tests of multinomial logistic regression model

Moreover, the Likelihood Ratio Tests in Table 5 showed that the independent variables which are income, pension status, physical independence, and gender are statistically significant (p-values 0.00, 0.04, 0.002 and 0.062 respectively). However, health insurance status variable is not statistically significant $(\mathrm{p}=0.267)$ for the dependent variable 'treatment cost' according to the survey dataset. 


\section{Pension State of Elderly}

Bangladesh has a frail provisioning for pension, whether it is practising entirely on Government sector, but it has been mostly overlooked in the private sector of the economy. Our dataset showed that $44.3 \%$ of the seniors received pension while $55.7 \%$ were not getting this economic protection opportunity. Large portion of the elderly who worked for private organizations were out of the pension safety net according to our dataset. About $31.3 \%$ of the respondent were government employee, while $68.7 \%$ were working in the private sector of the respondents.

\section{Pension Status}

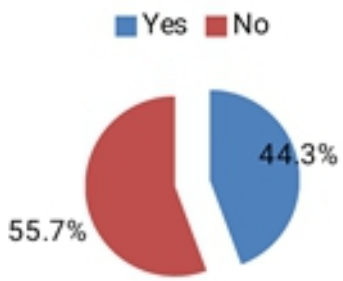

Occupation

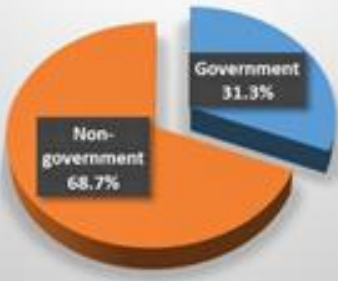

Figure 4. Pension status and sector wise occupation percentage of respondents

\section{Health State of Elderly}

In Bangladesh, disparity arises in the society because excessive healthcare expenses were met mostly by out-of-pocket payment of the respondents. In our study, only $15.7 \%$ of the total respondents had health insurance coverage, whereas the real scenery for the entire population was much more nominal. As can be seen from Figure 5, a high proportion of the elderly (83.7\%) were active and healthy. Notably, a higher percentage (98.33\%) of the respondents paid their treatment cost on their own.

respondents' Current health status, insurance coverage status and treatment cost bearing status

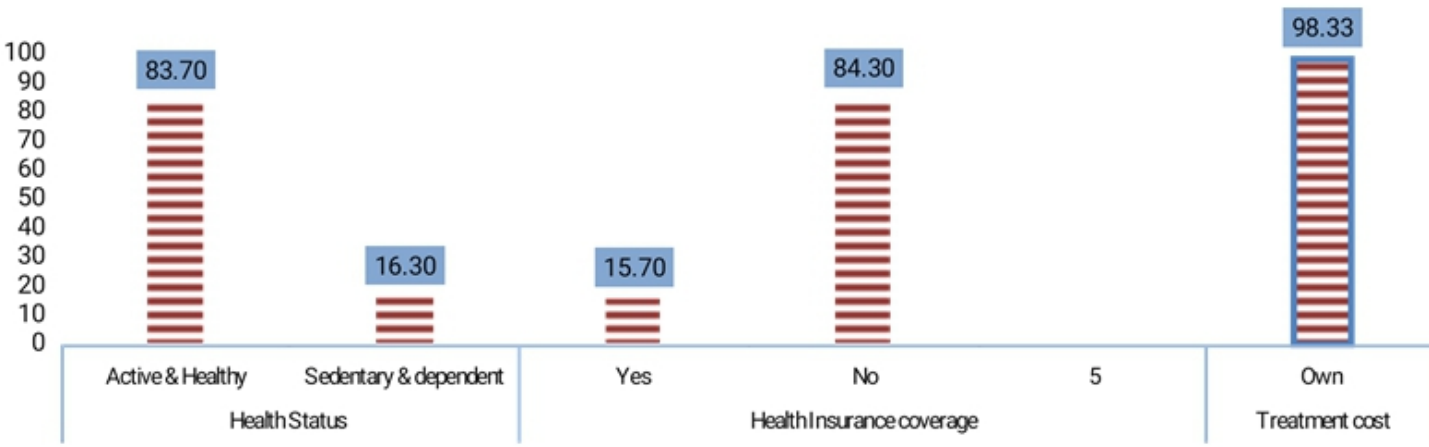

Figure 5. Respondent' health status, health insurance coverage and treatment cost status 


\section{Current health services facilities}

The report (2012) of Directorate General of Health Services (DGHS) of Bangladesh showed that there were 11,816 government primary healthcare hospitals and 124 Government secondary and tertiary hospitals in operation. Conversely, there were 7,623 registered private hospitals, clinics, and diagonostic centers in Bangladesh. Our study showed that most of the elderly prefered private hospitals due to the quality of services and the ease of services provision, whereas they did not prefer Government hospitals/health center with a cheaper cost due to low quality of services.

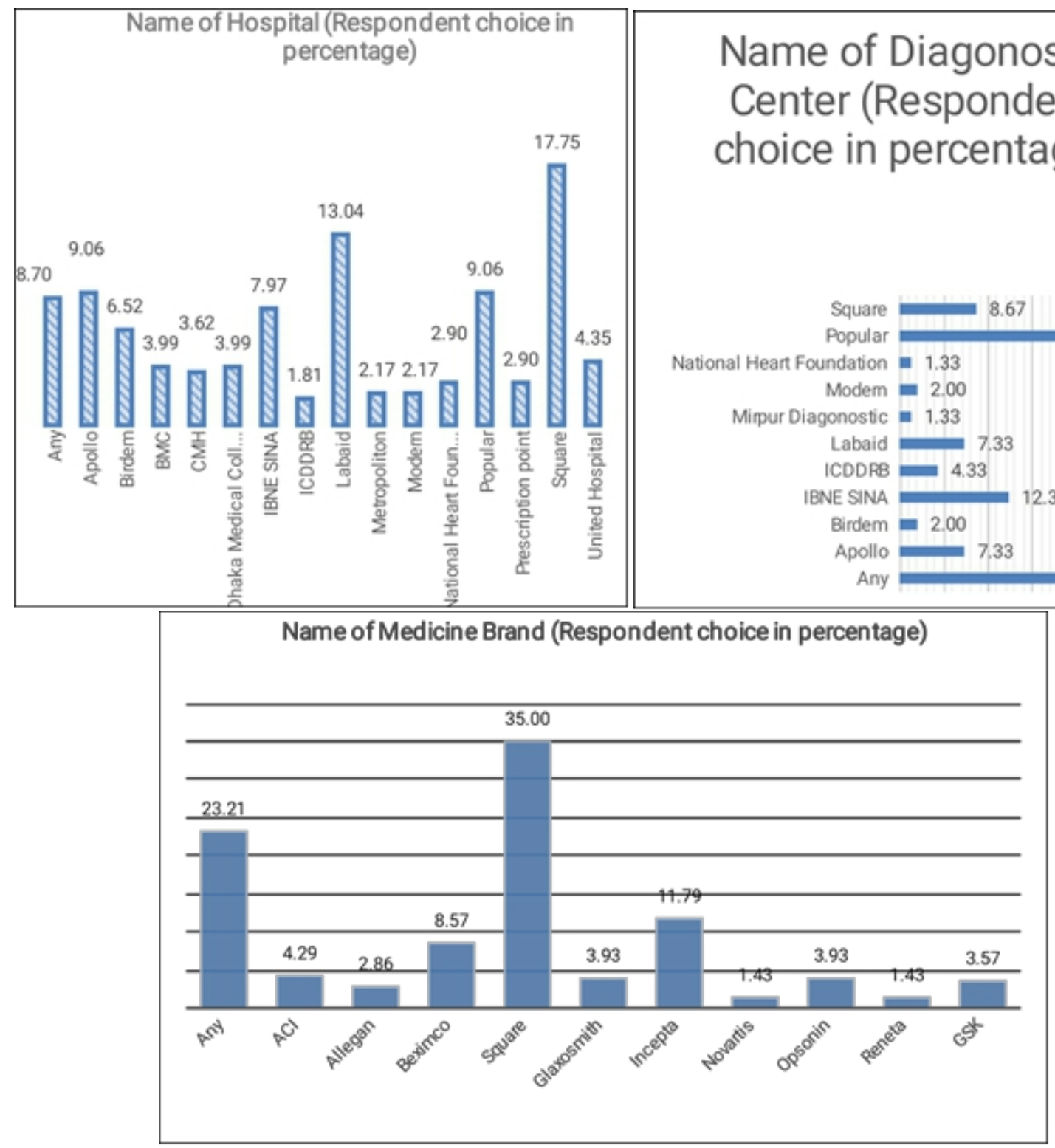

Figure 6. Respondents' preferences of hospital, diagnostic centers and medicine brand 
According to our dataset, more than $90 \%$ of the respondents prefered private hospitals and clinics rather than Government hospitals. Particularly, Figure 6 illustrated that Square Hospital Bangladesh (17.75\%) had the highest percentage of preferences by the respondents in private sectors, whereas Dhaka Medical College Hospital (renowned government hospital) had responded only with $3.99 \%$. Based on the respondents' diagonostic center preferences, it was shown that private diagonostic centers were prefered with very high percentages in contrast with Government diagonostic centers even though the price of the services in private sectors were adequately higher. Despite the cost, respondents prefered the private sectors due to service quality, modern equipment facilities, and also the credibility of diagonosis test results. It also showed that among the total respondents, about $25.33 \%$ elderly prefered 'Popular Diagonostic Center', 12.33\% and 8.67\% prefered 'IBNE Sina Diagonostic Center' and 'Square Hospital' respectively, and interestingly, all of them were private diagonostic centers. However minimal percentage of respondents prefered Government Hospitals for their prescribed diagonosis tests. In our study, most of the respondents' prefered medicine produced by Bangladeshi pharmaceuticals companies (specifically 35\% prefered Square pharmaceutical company, $11.79 \%$ prefered INCEPTA pharmaceutical company), whereas a low percentage of respondents prefered (such as, Novartis $1.43 \%$ ) international pharmaceuticals companies.

\section{Conclusion and Policy Framework}

In Bangladesh, the present demographic factors such as downward trend of fertility and mortality rates, migration, and the socio-economic factors such as lack of employment, force retirement, rapid urbanization, and progress in health care facilities are considered the main factors of increasing ageing population. Bangladesh is going through economic transition where ageing has a direct impact on socio-economic growth. Here, elderly suffer mostly from negligence, helplessness, and psychosocial and cultural complexities. They are still passing their days amidst the tender care and support mostly provided by their extended families without any remarkable backing from the national level.

In the context of population health of elderly, socio-economic condition is a significant determinant of health care. Our study reflected the present scenario and the forthcoming journey of elderly support in terms of economic and caring aspects. Elderly will need to have hospital, medicine, and nursing support based on the demographic point of view. However, from an economic point of view, viable pension and insurance support will be required to accommodate our ageing population. The dataset showed that only retired Government employees were getting pension, while the private sector employees were completely overlooked of pension benefit. To secure the 
ageing population, it is high time to think about the entire working people including the pension system for maintaining the current living standard. Moreover, government needs to ensure the private sector investors should be inevitable to provide their employees' pension, which would be a vital part of social safety net.

In Bangladesh, elderly are hardly prepared for their retirement age. According to our dataset, elderly mostly depend on pension but rarely depend on insurance. Our findings showed that significant indication of health care supporting impact on unbalanced financial liability of healthcare affected household living standard. Another significant cost driver is price inflation. Therefore, health-specific price inflation which includes core medicare goods $\&$ services, cost of doctors, nurses and advanced diagnostics has been always higher than the general inflation. This study suggested that Bangladeshi citizens should rearrange their health care financing scheme to overcome the financial liability for upcoming days.

The limited practice of health insurance coverage made the ageing people more dependable on their out of pocket for all types of treatment costs in Bangladesh. However, people are mostly covered by insurance in every sector in the developed countries. Interestingly, in Bangladesh, there are more than eighty insurance companies providing different insurance policies, but very few people are getting insurance benefits in reality. Therefore, Bangladesh Government should come forward with solid financial provision so that the insurance company's existing role would be more credible and effective. Political support is very much needed in this sector to improve the current scenery of ageing problem in Bangladesh.

Our study suggested that a considerable national policy is required immediately for the development and reforms of the health care of ageing population in Bangladesh. The following recommendations are made according to our study and also may be incorporated in the National policy of social security system in Bangladesh.

$>$ Declare the citizen of 60 years and above as "Senior citizen" by Bangladesh Government through legislation. Hence, legislation should be instituted properly so that children cannot neglect their ageing parents.

$>$ Formulate the 'Older Pension Association (OPA)' nationally with a detailed database of the elderly citizen for all employees working in both public and private sectors.

$>$ Formulate the 'Social Insurance Authority' nationally with a detailed database of elderly.

$>$ Enhance the involvement of all public and private insurance companies to introduce old age insurance for their retirement life. 
$>$ Introduce (public, private or self-employed) more monetary security tools for elderly such as pensioner sanchayapartra, bonds, fixed deposit scheme, and DPS scheme of savings with the highest feasible benefits by all the commercial banks and financial institutions.

$>$ Formulate a specialized bank for elderly to provide all the monetary tools in one roof with highest special rate of interest.

$>$ Ensure minimum treatment cost by government subsidy for elder in all the public and private hospitals.

Make sure that all employees in Bangladesh have their individual annuity plan from their early age of job or business to broaden their retirement age security.

$>$ Ensure special discount for public/private transports fare for elderly and also provide special monthly discount transport card for them.

$>$ Encourage social services companies to provide more effective home care for elderly with discount price.

$>$ Subsidize (i.e. government relief fund) the catering companies for supplying balanced cooked meal to the elderly.

$>$ The security agencies could offer a special security alert app for the elderly.

$>$ Specialized pharmacies can be assigned for specific areas or registered elderly to refill their medicine on time at their home.

$>$ Finally, develop an integrated social protection and safety net program for elderly.

\section{References:}

1. Ali, M. (2013). Population ageing in Bangladesh: A Reinless Challenge. The News Today, The daily News Paper.

2. BDHS. (2011). Bangladesh Demographic Health Survey. National Institute of Population Research and Training (NIPORT), Dhaka, Bangladesh.

3. Bengtsson, T., \& Scott, K. (2011). Population Ageing and the Future of the Welfare State: The Example of Sweden. Population and Development Review, 37(1), 158-170.

4. Bergstrom, M., Holmes, M., \& Pecchioni, L. (2000). Lay theories of successful ageing after the death of a spouse: a network text analysis of bereavement advice. Health Communication, 12(4), 377-406.

5. DGHS. (2012). Health bulletine. Director General of Health Services, Bangladesh Government.

6. Islam, A. (2008). Acculturation Preferences among Bangladeshi Immigrants in London and Malmoe. Siirtolaisuusinstituutti, Web Reports37. 
7. Jalal, S., \& Younis, M. (2014). Ageing and Elderly in Pakistan. Ageing Int., 39, 4-12.

8. Jeremy, D., Goldhaber Fiebert, David M., S., Monica S., F., \& Jay, B. (2015). Will Divestment from Employment-Based Health Insurance Save Employers Money? The Case of State and Local Governments. Journal of Empirical Legal Studies, 12(3), 343-394.

9. Look, K., \& Arora, P. (2016). Effects of the Affordable Care Act's young adult insurance expansion on prescription drug insurance coverage, utilization, and expenditures. Res Social Adm Pharm., 12(5), 682-698.

10. McClellan, C. (2017). The Affordable Care Act's Dependent Care Coverage Expansion and Behavioral Health Care. J Ment Health Policy Econ., 20(3), 111-130.

11. Michel, J.-P., \& Robine, J.-M. (2004). A “New' General Theory of Population Ageing. The Geneva Papers on Risk and Insurance, 29(4), 667-678.

12. Montgomery, C., \& Peck, A. (1992). Introduction to Linear Regression. John Miley \& Sons, Inc.,USA.

13. Oeppen, J., \& Vaupel, J. (2002). Broken Limits to Life Expectancy. SCIENCE, 296(5570), 1029-1031.

14. Rahman, A. (October 2010). Getting and Staying Active in Later Life. The Daily Star.

15. Rahman, K. (2012). Policy Brief on Present Social Context and Elderly Population in Bangladesh. Unnayan Onneshan Bangladesh.

16. Rowshon, A. (2012). Ageing and Health : How far Bangladesh is prepared? Journal of Shaheed Suhrawardy Medical College, 4(1), 1-2.

17. Schultz, H., Higham, J., \& Michael, S. (2014, October 31). The Informal Caregiver: A Qualitative Assessment of Needs and Requirements. Family Medicine \& Medical Science Research, 3(4).

18. Sultana, T. (2011). Expectations, Realities and Coping Strategies of Elderly Women in a Village of Bangladesh. Bangladesh Development Research Working paper Series, Bangladesh Development Research Center (BDRC).

19. United, N. (2005). World Population Prospects. Department of Economic and Social Affairs, Population Division, United Nation.

20. Vedder, P., \& Virta, E. (2005). Language, ethnic identity, and the adaptation of Turkish immigrant youth in the Netherlands and Sweden. International Journal of Intercultural Relations , 29(3), 317-337.

21. WPP. (2012). World Population Prospects. Department of Economic and Social Affairs, Population Division, United Nation. 